Article

\title{
Direct Impacts of an Urban Living Lab from the Participants' Perspective: Livewell Yarra
}

\author{
Darren Sharp * (1) and Robert Salter \\ Curtin University Sustainability Policy Institute, Curtin University, Bentley, WA 6102, Australia; \\ R.Salter@curtin.edu.au \\ * Correspondence: darren.a.sharp@postgrad.curtin.edu.au
}

Received: 31 August 2017; Accepted: 18 September 2017; Published: 22 September 2017

\begin{abstract}
Urban living labs have emerged as transition arenas for undertaking process-oriented and reflexive experiments in the multi-stakeholder governance of sustainability. This paper evaluates Livewell Yarra, an urban living lab in Melbourne, Australia, that brought together academic researchers and community actors to engage in experiments for low-carbon living. This paper evaluates transition team experiments in governance of the lab itself and community experiments in carbon reduction that took place in people's homes and small group settings known as decarb groups. This paper's primary research question is: what are the direct impacts of urban living lab experiments from the participants' perspective? The research methods utilised include action research, asset-based community development, participatory co-design and most significant change research. This paper evaluates experiments in low-carbon living through data collected via stories of change from participant interviews. The results indicate that experiments in urban living labs create opportunities for social learning and empowerment, but also raise issues of leadership and ownership of transition governance. The findings suggest that Livewell Yarra could have benefited from clearer agenda setting and continuous monitoring to feedback results. The paper concludes by suggesting future research directions that utilise the operational processes of transition management to support experiments in urban living labs.
\end{abstract}

Keywords: urban sustainability; urban living lab; sustainability transitions; urban experiments; action research; transition management

\section{Introduction}

With over half the world's population now living in cities, the 21st century has been justifiably called the urban century [1]. As geo-strategist Parag Khanna's work demonstrates, the locus of the world order is shifting away from nation states as cities become the new "islands of governance" and "experimental laboratories" where solutions to a range of sustainability challenges will arise [2]. Urban living labs (ULLs) are a form of transition arena, a multi-actor governance instrument characterised by a normative focus on achieving sustainability goals which are determined by participants themselves through their interactions [3]. ULLs provide arenas for niche experimentation and learning through user-centred design and co-creation between diverse stakeholders at the local urban scale [4].

Australia is one of the most urbanised countries in the world with nearly $90 \%$ of the population living in urban areas [5]. Livewell Yarra was an Australian urban living lab that brought together researchers from Curtin University, a local government partner and community participants to trial niche experiments in low-carbon living. The ULL project was geographically located in the City of Yarra, a small inner urban municipality in Melbourne, and took place from June to November 2015. It used action research [6] based on normative objectives to encourage the transition to more sustainable lifestyles. 
Sengers et al. [7] note that experimentation "occupies a central position within the field of sustainability transitions' (p. 15), and can be defined as "an inclusive, practice-based and challenge-led initiative, which is designed to promote system innovation through social learning under conditions of uncertainty and ambiguity" (p. 21). Experimentation occurred in Livewell Yarra through the governance processes of the urban living lab itself via transition team meetings and activities undertaken by community participants to reduce their carbon emissions.

The action research was designed to catalyse the formation of place-based small groups known as decarb groups, as a vehicle for social learning and experimentation in low-carbon living. The research goals were to generate community action for low-carbon living through niche experiments at the household, small group and community level. It was envisaged that community participation would outlast the short time frame of the ULL with the support of active citizens working together for the governance of sustainability transition in their local community and beyond.

The methods used for the research were transdisciplinary and generative in nature and included asset-based community development, participatory co-design and most significant change (MSC). These asset-based approaches focused on leveraging the strengths (gifts of the head, heart and hands) of participants to encourage self-directed learning, inquiry and action. In-depth interviews were conducted face-to-face and via telephone with 16 Livewell Yarra participants to understand the most significant changes experienced through their involvement in the urban living lab from their perspective.

This paper's main research question is: what are the direct impacts of urban living lab experiments from the participants' perspective? Quotes from MSC interviews related to social learning, empowerment, experimentation, ownership and leadership examine these direct impacts in the context of low-carbon living. These stories of change provide transition studies researchers with qualitative data on the personal experiences of urban living lab community participants in the governance of urban sustainability transitions.

\section{Urban Living Labs}

Urban living labs are "transition arenas" which provide "protected spaces" for experimentation and learning in the context of governing urban sustainability transitions [8-10]. Several urban living lab addressing sustainability challenges and the transition to low-carbon cities have emerged in recent years across European cities in Sweden, the Netherlands and the UK [11].

The concept of living labs emerged from the work of William Mitchell at Massachusetts Institute of Technology (MIT) [12] and have spread to numerous countries with 395 labs listed as members of the umbrella organisation ENoLL [13]. According to Schumacher, "William Mitchell argued that a Living Lab represents a user-centric research methodology for sensing, prototyping, validating and refining complex solutions in multiple and evolving real life contexts" [14] (p. 5). Urban living labs have emerged more recently to create open innovation ecosystems across a range of areas, commonly including sustainability related areas such as the built environment, energy and transportation systems. The Governance of Urban Sustainability Transitions project (GUST), involving researchers from Sweden, the UK, the Netherlands and Austria, has identified five key characteristics of urban living labs which are integral to its design and processes: "geographical embeddedness, experimentation and learning, participation and user involvement, leadership and ownership, and evaluation of actions and impacts" [15] (p. 1).

Nevens et al. [16] observe that urban transition labs act as important innovation incubators that add an "extra dimension to the local urban governance approach" (p. 116) through the creation of social learning environments that are led by a transition team able to embrace a variety of diverse perspectives in negotiation with key stakeholders "in a strongly reflexive manner" (p. 121).

Given the learning by doing nature of urban living labs, it is crucial for researchers engaged in leading these projects to evaluate the effects of such experiments in transition processes. Schliwa et al. [17] have developed a threefold typology of "direct, indirect and diffuse impacts" to 
understand the success of urban living lab projects. Direct impacts can be measured from an economic, ecological or user perspective; indirect impacts could be follow up activities where knowledge transfer or policy reform occurs at the regime level; and diffuse impacts refer to a change in normative values which is difficult to detect and often only retrospectively [17].

Researchers from the Finnish low-carbon labs program called Carbon-Neutral Municipalities used data derived from "the perspective of the local community" (p. 150) and documented their "personal experiences" of being involved in local experimentation [18]. The participants interviewed in the Finnish case study emphasised the perceived importance of small step-by-step achievements and practical demonstrations of low-carbon solutions which helped legitimate the program. In the same vein, this paper will explore the direct impacts of urban living lab experiments from a community perspective through MSC interviews with Livewell Yarra participants.

\section{Transition Governance}

Sustainability transitions is an emerging field of scholarship with a multi-disciplinary approach to research informed by science and technology studies, complexity theory and innovation studies [19]. Transition studies proposes that incumbent socio-technical systems exhibit strong path-dependencies and are comprised of networks of actors that include individuals, firms, and institutions which are tightly interrelated [19].

Sustainability transitions scholars developed the three-level model [20] comprised of niches, regimes and landscapes, often summarised as the multi-level perspective, or MLP [21]. The multi-level perspective is conceived as a nested hierarchy comprised at the micro-level of niches, which are the site of radical innovations; the meso-level of regimes, which provide stability through technological trajectories; and the macro-level of landscapes comprised of deep and slow-changing structural trends [22]. Niches situated at the micro-level can incubate "radical novelties", provide locations for "learning processes" and "space to build the social networks which support innovations" [22] (p. 1261). Sustainability transitions rely on niches to provide "protective spaces" for "radical alternatives" to develop and become viable [23]. Transition arenas are social environments where "alternative visions, agendas and actions" can be supported through social innovations outside of the dominant market or policy logic [3] (p. 85).

The MLP and related concepts have emphasized transition processes from a macro or systems level perspective which according to some scholars "might have come at the expense of a more actor-oriented and agency-sensitive analysis" [24] (p. 992). Other transitions research addresses agency more directly through a focus on governance issues and examines how various actors can be mobilised for sustainability. Transition management offers an approach to governance and an operational model for sustainable development that is process-oriented and "supported by experiences from practice" [3] (p. 85). Transition management has developed a reflexive cycle to mobilize actors known as change-agents (frontrunners) through transition arenas for experimentation and "learning by doing" [25].

Transition management projects are coordinated by a transition team which is established to "manage both content and participatory processes" [8] (p. 53). The transition team is typically composed of academic researchers, city officials and other stakeholders that "prepares, documents, analyses, monitors, co-ordinates, manages, facilitates and evaluates the whole process, but also chooses the participants and feeds them with background information and detailed knowledge" [26] (p. 31).

The direct participation of researchers in coordinating experiments is a relatively new aspect of urban transition scholarship which as Nevens et al. [16] (p. 113) observes, has been dominated by "an analytical rather than an action focus". Wittmayer and Schäpke [27] (p. 484) have developed a systematic analysis of the "changing roles of researchers in process-oriented approaches" like transition management, a new development for sustainability science, which has traditionally privileged "descriptive" and "knowledge-first" approaches. 
As Wittmayer and Schäpke [27] (p. 487) point out, transition management is a process-oriented mode of sustainability science that uses action research to drive transformation: "In both action research and transition management, the explicit goal of "action" is real-life change. Researchers actively facilitate or participate in the learning process and in the actual experiments (e.g., the creation of paradigms or lifestyle icons of sustainability), they support in policy formulation, while at the same time observing, reflecting and analysing these actions and their relations to the long-term vision."

The urban living lab case study developed in this paper evaluates real-life changes from the perspective of participants using qualitative data derived from action research. The authors of this paper were directly involved in setting up and coordinating social learning activities and experiments in low-carbon living with other members of the transition team. We use transition management in this paper as a lens to describe governance activities and evaluate the process-oriented results of our research, in line with other transition scholars using similar approaches [28].

\section{Livewell Yarra Case Study}

Livewell Yarra was an urban living lab that enabled community participation to trial experiments in low carbon living with an emphasis on carbon reduction and wellbeing. The inner Melbourne municipality of City of Yarra was chosen as the site for the urban living lab for two main reasons. Firstly, the local council shared Livewell's low-carbon values and aspirations and agreed to support the urban living lab with free venue use, promotional assistance and advice. It was also Victoria's first carbon-neutral council and Australia's first One Planet Living council, and it had initiated the Yarra Energy Foundation to help the local community to decarbonise. Secondly, there was a relatively high level of awareness and concern about climate change and the need to reduce emissions in the Yarra community. A strategic principle often adopted by change agents is to start where change will be easiest, in order to maximise the chance of success and build confidence in the project's early learning stage. With the experience gained, action in more challenging settings can then be attempted.

Livewell Yarra was concerned with the collaborative governance of climate change mitigation and adaptation at the household, small group and local community level. Livewell Yarra brought together academic researchers from Curtin University, project officers from the City of Yarra (local government), members of the local community (urban living lab participants) and the Cooperative Research Centre for Low Carbon Living (research funders). As an action research project, the academic leadership team led the formation of the urban living lab by reaching out to self-selected change-agents known as "frontrunners" [8], local community members who were actively engaged in climate change causes and had already taken steps to reduce their household carbon emissions.

These people coalesced into a transition team overseen by the academic researchers who convened monthly meetings to develop the operational design and functions of the urban living lab. The lab's purpose was to develop and trial a particular way to actively engage ordinary community members in supporting each other to reduce their own carbon emissions in the first instance, but also to participate in community action and advocacy to help reduce the broader society's emissions. The transition team was directly involved in setting up the urban living lab, engaging participants and enabling them to undertake a variety of niche experiments through social leaning in small groups, topical workshops, projects, meetings and other activities designed to encourage action-based forms of low-carbon living.

While there is a substantial amount of information about climate change and carbon reduction held within governments, research institutions and certain businesses and not-for-profits, much of this information does not filter down to the general community level, and so there is a need to convey this, and to convey it in a language and form that is accessible and appealing to community members. Moreover, the actions that these community members need to then initiate to reduce emissions usually require more than just the provision of information. Lifestyle changes are usually required, and new actions taken that may run counter to the actions, values and norms of peers and the general community. 
In this context, the project initiator saw value in bringing people together in small peer support networks, or decarb groups, which met regularly and in which members shared information, encouraged and assisted each other, modelled new ways of doing things, and help to create new norms and expectations of low-carbon living. In addition to the information shared in groups and workshops, the academic researchers (this paper's authors) and transition team provided additional information through a website, social media channels, and an email newsletter.

\section{Research Methodology}

The authors used action research to establish and steer Livewell Yarra as an urban living lab and to plan, act, observe and reflect on transition governance experiments. This involved monthly meetings with the transition team, the creation of small peer support networks (decarb groups), topical workshops on low-carbon living (First Thursday workshops), asset mapping and co-design workshops, along with participant interviews (see Table 1). Livewell Yarra participants were given a consent form to sign and information statement that explained the process in detail before deciding to participate in research activities.

Table 1. Overview of Livewell Yarra action research including urban living lab (ULL) activity, research methodology and participants involved.

\begin{tabular}{ccc}
\hline ULL Activity & Research Methodology & $\begin{array}{c}\text { Participants } \\
\text { Involved }\end{array}$ \\
\hline Transition team & Planning discussions and operational design. & 12 \\
Decarb groups & Small group meetings, niche experiments and social learning activities. & 100 \\
First Thursday workshops & Presentations, panels and group discussions. & 120 \\
Asset mapping workshops & Asset-based community development. & 12 \\
Co-design workshop & Participatory co-design and rapid prototyping. & 6 \\
Participant interviews & Most significant change (MSC). & 16 \\
\hline
\end{tabular}

Several decarb groups were formed over the duration of the urban living lab as the main site of activities, with participants mostly comprised of local community members from the City of Yarra. The project initiator considered measuring the carbon reduction achieved by decarb group members, but decided against this given the relatively small number of participants, the short duration of the research phase, the range of extraneous variables that might affect the level of carbon emissions, such as variations in weather, household size and daily routines (for other than carbon reduction reasons), and the difficulty of determining what emissions changes could be attributed to participation in the action research. Thus, qualitative assessment alone was employed, as described below.

Two asset mapping workshops were held in August 2015 with 12 participants from a number of local decarb groups. This activity used asset-based community development (ABCD) [29], a strength-based tool to reveal participants' latent strengths and build capacity to take action in the areas of low-carbon living. Participants were invited to map individual assets, referred to as gifts of the head (things I know about), gifts of the heart (things I care about) and gifts of the hands (skills I know how to do). These assets took many forms including knowledge about sustainable housing, passion for bike riding and hands-on skills in composting and waste minimisation.

A co-design workshop was held in September 2015 to develop an early stage buddy system concept to match bicycle riders and non-riders in the City of Yarra, the brainchild of two Livewell Yarra participants. The workshop facilitator (the PhD student) used participatory co-design to help participants brainstorm as many ideas as possible related to the concept [30]. People then formed into small design teams and collaboratively developed simple paper-based "rapid prototypes" using markers and paper [31].

MSC interviews were conducted as a participatory evaluation method to gather "stories of change" from Livewell Yarra participants between December 2015 and January 2016. According to Dart and Davies [32], stories are a core aspect of the MSC approach as they encourage "non-experts" 
to contribute their evaluation reflections and keep focused on "concrete outcomes" instead of referring to abstract criteria. These interviews revealed the direct impacts experienced by participants through their involvement in Livewell Yarra, mention challenges that had arisen and discuss ideas for future activities.

In the following sub-sections we use a transition management lens to outline the approach of Livewell Yarra through the activities of orienting, agenda setting, activating and reflecting [33]. These functions will be used as a descriptive frame to articulate the research methods for experiments in low carbon living.

\subsection{Orienting}

The transition team began meeting in May 2014. Members had been recruited through local organisations, educational institutions and informal networks. The task of the team, as already stated, was to get the urban living lab underway. This involved planning a launch, producing a video, initiating a website, a newsletter and social media, arranging workshops, and developing a plan for the formation of decarb groups. However, the transition team also functioned as a decarb group itself, in order to trial the approach that would be recommended to future participants. For about half of the time in each meeting, team members discussed changes they had initiated to reduce their own carbon emissions, successes they had, problems they faced, and ideas for further action. Other members offered suggestions and recounted their own experience.

Livewell Yarra was launched by the City of Yarra mayor, Cr Philip Vlahogiannis at Fitzroy town hall in Melbourne on 5 March 2015 in front of 200 people, with keynote speeches by Professor Ross Garnaut, author of the Garnaut Climate Change Reviews, and Fiona Armstrong, the founder of the Climate and Health Alliance [34]. People at the launch were asked to indicate their interest in participating in the Livewell action research and were invited to self-organise into decarb groups-small peer groups of 6-12 people from the local community, which would become the locus of social learning for the project. The purpose of these groups was to help living lab participants reduce their carbon emissions while maintaining or enhancing their wellbeing.

Before decarb groups commenced, participants were invited to attend an orientation session. In these sessions they got to know each other, learnt about how Livewell Yarra and decarb groups would function, heard an introductory talk on carbon reduction, and indicated what topics they would like to know more about, particularly through workshops.

\subsection{Agenda Setting}

Agenda setting occurred at two levels. For the whole project the agenda was set by the researchers and the transition team, but at the decarb group level an agenda was suggested by the researchers and transition team, but group participants ultimately determined their own agenda.

Looking at the first of these levels, a key goal of the transition team was to normalise low-carbon living, that is, to present it as a very achievable, perfectly acceptable way of living that ordinary people practised, as well as presenting it as an attractive way to live. To this end, in an introductory video on the subject and in photos and stories on the website, and actual participants from the transition team became the face of the project and were shown practising and enjoying low-carbon living.

The researchers facilitated a community visioning exercise with members of Livewell Yarra using an approach called "Dream Pair Share". Participants in this exercise paired off and created three phrases or images to describe the community they would most want to be part of at some point in the future. Next, the pairs shared their visions and the reasons behind them with their partner, then chose three dreams they would like to bring to the larger group.

Teams put each dream on a Post-it note and added them to the appropriately titled dream wall. Similar dreams were clustered together and people picked the cluster they were most drawn to. Groups then self-organised around various project ideas on cycling, the sharing economy, community connections and participatory democracy. 
Regarding the agenda setting at the decarb group level, this was less straightforward. The agenda suggested by the transition team was only partially followed by the groups. This was of course their right, but some participants proffered the view some months later that there was not enough structure in the groups. This suggests differences of opinion within each group, with some members being more task oriented and others more interested in more informal, perhaps more socially oriented sessions. This issue reflects the fact that adults, when not in a formal work or educational setting, may not readily accept working within a structured format.

\subsection{Activating}

Following the Livewell launch and orientation sessions six new decarb groups were formed, one of which was based on an existing neighbourhood group. Later that year three other groups were formed, each by an individual drawing people together in their own neighbourhood. Thus, a total of 10 groups were started, including the transition team which also functioned as a pilot decarb group.

As previously stated, these groups enabled participants to reduce their own carbon emissions and to help their peers to do likewise. They were self-directed and set their own agendas, and their activities included discussion, listening to speakers, and shared carbon reduction projects such as waste reduction. As well, a series of First Thursday workshops with subject matter experts was arranged on topics of interest to provide additional information and to build links across the groups.

The decarb groups were asked to meet monthly at participants' homes, public libraries or community halls for the duration of the research phase and decide on actions to reduce personal emissions, take these actions, observe their progress or lack thereof, and discuss these experiences with other group members. Transition team members had tested and refined this process for some months through a pilot decarb group that was formed in the lead up to launch and before the start of the research. Decarb groups were free to meet just for the six month duration of the urban living lab, or to keep meeting if members desired. Some groups are still meeting, or still cooperating in a more informal way, and so there are ongoing benefits of their involvement.

A variety of experiments emerged from the governance of Livewell that was led by the project initiator with support from the PhD student and a small group of community volunteers, which together comprised the transition team. This leadership group held monthly meetings with rotating chairs, ran internal workshops and planning sessions. The transition team even started its own incorporated association with membership and elected office bearers, to give Livewell Yarra the opportunity to continue as a community-led movement beyond the relatively short time span of the research project.

Decarb groups formed after the launch of Livewell and were empowered to undertake further experiments at the household and community level such as changing energy providers, increased bicycle use, improvements to home insulation, waste-reduction activities and soft plastics recycling, group purchasing of home solar panels and the creation of an urban agriculture initiative. This occurred through information handouts provided to participants by the transition team and via "how-to guides" which provided practical resources on topics related to low-carbon living made available on the Livewell website (https:/ /livewell.net.au/how-to-guides) [35].

\subsection{Reflecting}

The transition team had opportunities to informally reflect on Livewell's approach through the monthly meetings convened during the course of the action research. Transition team meetings began with a round table reflection on the progress each member was making in their own attempts to reduce carbon emissions. Extensive minutes were kept, documenting monthly meetings, individual actions, questions to follow up and next steps.

Decarb group participants were given evaluation forms to fill out at the conclusion of the orientation sessions and these were used to monitor peoples' experience of the establishment process. Consideration was given to a "Livewell Tracker", or group survey instrument that would enable 
participants to reflect on their experiences on a monthly basis, but it was decided that the qualitative interviews to be conducted at the end of the research phase would be performing a similar function.

MSC interviews were undertaken that enabled participants to reflect on their past experiences in the urban living lab and highlight the greatest areas of impact from their own personal perspectives. This interview data was very useful in terms of understanding direct impacts of participants, but did not allow for ongoing monitoring and evaluation of the transition arena and governance process itself.

Loorbach [25] (p. 177) observes that "continuous monitoring is a vital part of the search and learning process of transitions." One can only speculate on the effect that continuous monitoring might have had in relationship to the transition arena's operations. However, governance issues related to ownership and leadership did emerge within the transition team, a common challenge for urban living labs that will be discussed in the next section.

\section{Direct Impacts of Participants}

In this section we discuss the results using selected quotes chosen to shed light on the direct impacts experienced by Livewell Yarra participants through their involvement in various activities related to social learning, empowerment, experimentation, ownership and leadership of Livewell Yarra as an urban living lab. The quotes referred to are taken from one-on-one interviews with participants conducted after the conclusion of the formal research phase (December 2015 to January 2016). The quotes were selected from amongst 16 interviews as representing the most significant changes that the project has achieved from the perspective of participants.

\subsection{Social Learning}

Reed et al. [36] (p. 4) define social learning as "a change in understanding that goes beyond the individual to become situated within wider social units or communities of practice through social interactions between actors within social networks." According to Loorbach [25] (p. 168), social learning is one of the key principles of transition governance that actors in transition arenas rely on to reveal a "variety of options" and to reframe "problems and solutions" via interaction between stakeholders.

In terms of Livewell Yarra, social learning took place in a variety of contexts but mostly through transition team and decarb group meetings, both small group settings conducive to peer-based knowledge sharing. These interactions were held informally in library meeting rooms and people's homes and followed a basic structure where participants went "round the circle" at the start of each meeting to share details of the carbon reduction actions they had taken in the last month with an open invitation for other group members to ask questions or make suggestions related to tips, support and advice designed to assist peers in reaching their goals. This "round the circle" activity created a new social unit conducive to learning through shared experiences of mutual support opening a space for the emergence of new practices as exemplified by this quote from a Livewell participant:

"Look, I am a social being and I do get influenced by others, and get my energy from being with others, and so I've found having a community of like-minded people who are all trying to work in a similar area really a useful way of spurring me to more action. And I've found the other members of the group very inspiring and each meeting, particularly when initially we would do the rounds about, people would say what they were doing to reduce their carbon emissions, and I always got something out of that, found some useful piece of information that someone was doing that I thought, "I could do that" that I perhaps hadn't thought about."

The above-mentioned decarb group member's direct experience of social learning accords with civic engagement author Peter Block's [37] (p. 93) description of the small group as "the unit of transformation" whereby conversation is leveraged to build community through relatedness: "At these moments, citizens experience the intimacy of the small circle and are simultaneously aware that they are part of a larger whole that shares their concerns." Livewell used the small group setting as the primary 
arena for knowledge generation via social interaction for various reasons. It reflected the self-directed nature of learning preferred by the project initiator, but was also a pragmatic decision given that the transition team, comprised of this paper's authors and community volunteers, was unable to offer facilitation support beyond the first month of decarb group meetings in most cases. The direct impact of individuals coming together and learning from peers by relating to one another in a small group setting through conversation is captured in this quote from another decarb group member:

"That's one of the big pluses I think with Livewell is the knowledge sharing, yeah, definitely. I mean I guess a few of us think we already know what there is to know, but you're often surprised by people coming up with things that you sort of perhaps haven't thought about, so that's a very important part of it. ... So for me I suppose that's helped me change my attitudes a bit that you can get valuable information by talking to people not just sitting in front of a computer screen, or reading your books or whatever."

\subsection{Empowerment}

One of Livewell's major objectives was to build capacity for participants to take actions to reduce their carbon emissions and engage in low-carbon living through small changes made at the individual or household level. As Loorbach [38] (p. 284) observes, empowering niche actors is a key objective of transition management to: "influence and empower civil society in such a way that people themselves shape sustainability in their own personal environments, and in doing so contribute to the desired transitions to sustainability."

Livewell participants took various actions to reduce their carbon emissions via social learning in decarb group meetings and First Thursday workshops. Participants were engaged through peer-based knowledge sharing to self-select carbon reduction actions most relevant to them personally in the context of their household with an emphasis on stationary energy use and transport. As Schäpke et al. [39] (p. 8) notes: "Engagement is likely if a felt empowerment is linked to an increase in awareness of and felt responsibility for sustainable behaviour—or simply, if sustainability-oriented actors feel empowered." In this quote a Livewell participant talks about how decarb group conversations with peers influenced him to take action and switch household electricity suppliers despite initial doubts:

"In our group someone recommended Powershop so we changed our electricity supplier. Prior to that I had encountered ads for Powershop but I was rather sceptical or cynical. But when one of our group members suggested it we followed it up and then made the change over."

The most significant achievements emphasised by Livewell interviewees related to small changes in lifestyle. Another decarb group member reflected on her reduction in car usage and fewer emissions intensive transport choices, a direct impact of her participation in Livewell Yarra:

"I tend to be more pedantic about using my bike now to even go to the local shops and things like that. I try and pile my groceries onto my bicycle rather than use (the car)—so I tried to use the car as little as possible. I might use the car once a fortnight now.... If the weather's really bad, I use public transport ... 90\% of the time, I go to work on my bicycle ... even on days when I've thought "oh, I'll just hop in the car"-now, I tend to think "No, you won't, you'll hop on your bike!" So I get the benefit of being probably physically a bit fitter too."

A number of other Livewell participants took actions to reduce their carbon emissions by also switching to green electricity suppliers, making improvements to home insulation and draft-proofing windows and doors using a variety of technologies discussed during decarb group meetings. Others were inspired to take up group purchasing of rooftop solar and investigate divestment options related to their financial institutions and superannuation providers. 


\subsection{Experimentation}

Experimentation is key to driving system innovation in process-oriented approaches like transition management, as Loorbach [3] (p. 11) observes: "the only way that we can make progress in terms of sustainable development is to experiment and explore in a structured but flexible way, learning-by-doing and doing-by-learning, and through that process develop sustainably."

The planning and development of Livewell Yarra was an experiment in transition governance as the project initiator worked with the transition team, mostly comprised of community volunteers, to create an incorporated association with elected office bearers (outside of the research team), formal membership structure, model rules, and requirements to prepare financial statements and hold an annual general meeting. This association, Livewell Clusters, was created with the intention to give community participants the opportunity to carry low-carbon living experiments and decarb group activities forward beyond the conclusion of urban living lab research in November 2015.

However, the decision to create an incorporated association was not universally supported by all transition team members and, on reflection, may have distracted participants from more fundamental concerns related to the establishment and facilitation of decarb groups. As one member of the transition team stated in interview: "I think it's like "What are we doing? Where is this going?" I don't know why we're incorporated, for instance, and what benefits that has had."

Another major experiment was the First Thursday workshop series that was initiated by a member of the transition team and run by fellow team members. These workshops, as the name implies, were held on the first Thursday of every month and brought in expert presenters on a range of topics related to low-carbon living that included home energy use, reducing and recycling waste, how to have conversations about climate change, the sharing economy and the divestment movement. These workshops brought decarb groups from across Livewell Yarra together in a larger communal setting to discover and learn about various carbon reduction actions. This quote reflects how the First Thursday workshops complemented decarb group activities by exposing participants to additional opportunities for action and reflection:

"I think our group had quite a lot of us attend the workshops and they were really good, and they sort of sat well with the kind of things where you're getting more information. And then you sort of taking it back to your local group and then working out what it means for us and collectively and individually."

The authors of this paper, as research leaders, encouraged Livewell participants to start their own experiments in low-carbon living that were called "projects". As mentioned, two participants came up with the idea to develop a buddy system to match novice cyclists with experienced riders in the City of Yarra. The PhD student researcher ran a co-design workshop with six people who broke off into teams to develop two prototypes. The student researcher also facilitated four workshops with the bike project leaders to develop a business model canvas and set of value propositions, but this experiment did not advance beyond the concept stage.

Another form of experimentation related to social learning and empowerment that took place within decarb group meetings. One participant learned about the City of Yarra's "Community Growing Space" urban agriculture program through conversation with a fellow decarb group member. These peer-based interactions encouraged learning-by-doing, a key aspect of experimentation in sustainability transitions. This participant decided to initiate a planter box community garden experiment in her street as she describes in this interview quote:

"I am in the process of building a community garden. ... I've got a group of six households that once we've got the planter boxes, we'll open it up to everyone in the two buildings to have these garden beds on the footpath.... In terms of the community aspects ... the planter boxes ... they've brought together people who live together in an otherwise kind of alienating industrial area. We're getting together socially, we're also going to be making the streetscape a lot more pleasant and it will be for everyone (to) benefit from that." 


\subsection{Leadership and Ownership}

Urban living labs face a variety of engagement challenges whether led by academic researchers, local government or in collaboration with a range of stakeholders. In a review of various urban living labs across Europe, Voytenko et al. [11] (p. 51) highlight the centrality of getting leadership and ownership right in the design and execution of these initiatives: "There is an important coordination and management role for an ULL to be effective, although a delicate balance exists between steering and controlling. The ULL needs to remain flexible for different stakeholders to engage in its development and direction." In an evaluation of urban transition labs from a transition management perspective, Nevens et al. [16] (p. 121) found they are not coordinated by transition managers "in a top-down command-and-control style" but by a "variety of actors, participating in negotiation processes without a clear hierarchy nor demarcation of who is in or out of the city system."

Livewell Yarra's experiments in transition governance raised issues related to leadership and ownership that emerged as the activities of the urban living lab unfolded. The project initiator developed the initial concept for Livewell, appointed a PhD student to assist in the research, and recruited volunteers to join the transition team. The volunteers were members of the local community with an interest in reducing their carbon emissions and a concern for sustainability issues. Monthly meetings were held in the lead up to launch to discuss the formation of decarb groups and the development of activities to encourage social learning, empowerment and experimentation. There was a view by one member of the transition team that the project initiator could have shared key tasks and distributed responsibility across the team, but it is unknown what effect this might have had and whether or not it would have been a more effective approach:

"I guess the leadership model could be different in that sense....I feel that (the project initiator) could have shared responsibility more.... So it felt like that he's ... kind of holding onto those kind of reins, or he was not willing so much to share responsibility, and I think that could have helped us to take more responsibility early on."

The formative stages of Livewell involved monthly meetings with the transition team that were initially chaired by the project initiator. From the PhD student's perspective, the project initiator contributed a strong sense of direction, vision and purpose, which helped build momentum early on, rallied volunteers to join the project and helped make the urban living lab go from idea to reality. Another member of the transition team found the project initiator's style too top-down and also perceived that he was taking on too much responsibility for everything, but more so in the early days of the project's establishment:

"I think that some difficulties were (the project initiator's) ownership of Livewell. Because (his) style was I think to do everything rather than from the early stage have everyone doing lots of things. It's only later on it evolved where I think we ended up doing lots of stuff. But in the early days, to establish our feeling of ownership of what the project was about, to have help in the direction of it, whereas (the project initiator) had a very defined opinion about that, he wanted Livewell to achieve these things."

The PhD student makes the observation that the project initiator's leadership style did shift as he became open to more collaborative approaches and delegated an increasing number of tasks to other members of the transition team a few months into the process. This opening up and sharing of responsibility saw a member of the transition team initiate and lead the development of the First Thursday workshop series which, as discussed, became a major outlet for experimentation within Livewell. In this quote, another member of the transition team reflects on the challenging nature of getting the balance right when dealing with leadership issues of this nature:

"Look, I think it's tricky ... a really tricky one because there was a lot of stress initially on (the project initiator) trying to get things going, he was a bit of a lone-leader. And I think 
managing and garnering volunteers is always a challenge. And there's something to do with that role, how you delegate early and invite others in to engage others early on that maybe could have been done differently."

\section{Lessons Learned and Future Research Directions}

Our case study of Livewell Yarra has focused on the direct impacts of an urban living lab as experienced by decarb group participants and transition team members. The participant insights related to social learning has revealed the value of the "round the circle" activity, but the authors suggest that an additional reflexive process could have also been implemented. Decarb group meetings usually included the "round the circle" activity, but this exercise was not based on any specific action-based framework or conceptual tool which could have given it more structure and greater consistency across the groups. Other transition projects, like the Cooks River Sustainability Initiative, used design elements (i.e., processes, activities and project materials) along with "robust facilitation" to help participants build momentum for change through social learning and address the complexity inherent in these forms of governance experimentation [38] (p. 410). Livewell decarb groups were given resources such as a guide to reduce carbon emissions in the home, and domains of low carbon action, but participants were largely left to their own devices in terms of group facilitation.

The empowerment aspects of Livewell have been discussed in terms of the various small changes in lifestyle that participants experienced. Schapke et al. [39] (p. 8) observe that "frontrunners or change agents, as empowered individuals, are the first to realize possibilities for solving sustainability challenges, e.g., by establishing consumption and lifestyle alternatives." In the case of Livewell, participants were invited to join the urban living lab to reduce their carbon emissions in a supportive community-based setting. Given the short timeframe of the action research (six months) it would be useful to undertake follow-up interviews to ascertain whether the small lifestyle changes identified, like switching to green energy and reductions in car use, have been maintained by decarb group members since the conclusion of the research.

Livewell Yarra was not a transition management project in a precise operational sense and, in retrospect, the authors acknowledge that experimental governance undertaken by the transition team, especially in terms of setting up the urban living lab, could have benefited from much clearer agenda setting and reflecting. Agenda setting is a key component of the transition management process and "focuses on creating a shared sense of ownership and ambition for a sustainable future, thereby helping actors to integrate it with their own agendas and practices" [33] (p. 10). The creation of transition arenas involves problem structuring where the transition team develop "a vision, an agenda, and a social commitment to sustainability values" [8] (p. 54). The authors of this paper, as project initiator and PhD student, did put in considerable time to develop the narrative, framing and branding of Livewell with support from the transition team. This resulted in the development of a communications plan, introductory video, website, social media and email newsletter as mentioned. However, a more coherent vision of future images and pathways (transition agenda) towards low-carbon living in the City of Yarra (the transition arena) could have been created in the project. The development of such a vision by the transition team could also have addressed some of the leadership and ownership concerns raised during participant interviews.

Actor competency is another key aspect of transition arenas related to understanding the complexity of the problem space, the capacity to reflect on practice and the ability to relate practice back to the problems being addressed [40]. In the case of Livewell Yarra, transition team members (apart from the academic researchers) consisted of people from the local community interested in carbon reduction and low-carbon living. Some of them had practical experience in home improvements related to insulation, draft-proofing, composting and recycling, but none had expertise in transition governance, which was also true of the academic researchers. This highlights the need for greater capacity building in this emerging field of study, and it is encouraging to see a massive open online 
course on "Greening the Economy: Sustainable Cities", developed by Lund University with units on urban living labs, recently being made available [41].

Reflecting was also another aspect of the project that could have been improved. As discussed, the authors did not undertake continuous monitoring of Livewell, which might have brought to light some of the issues that were raised during participant interviews related to sharing responsibility and task delegation. Monitoring in transition management involves different tasks including monitoring arena actors, the transition agenda and the transition process itself "with regard to the rate of progress, the barriers, and the points for improvement" [8] (p. 56). From a living lab perspective reflecting takes place through iterative learning loops so that "experiments are conducted, monitored, and conducted again with improvements from the previous round to generate useful knowledge in a real-life setting" [42] (p. 167). Formal monitoring in Livewell only took place via MSC interviews conducted by the $\mathrm{PhD}$ student at the conclusion of the action research. Such monitoring throughout the project may have resulted in changes to the running of transition team meetings earlier on and changes in leadership style.

In light of these observations, future action research could more precisely bring together the operational model of transition management (orienting, agenda setting, activating and reflecting) [33] with insights from the emerging literature on urban living labs [9-11] to provide a more theoretically grounded and empirically tested process structure for further experiments in transition governance. Additionally, it would be interesting to evaluate whether the development of transition governance competencies in transition team actors affects the governance of future urban living lab experiments. The authors hope the Livewell Yarra case study, the direct impacts of participants and discussion of results provides other scholars, urban living lab facilitators and community stakeholders alike with insights for related experiments in transition governance for sustainability.

\section{Conclusions}

This paper has evaluated Livewell Yarra, an urban living lab that sought to support community members to undertake experiments in low-carbon living at a household and community level. Urban living labs are multi-stakeholder transition arenas that may include researchers, representatives of government, organisations that initiate or fund a project, and community members, and this was the case here. It provided a supported small-group setting in which community participants could try out new actions, drawing on information and encouragement provided by fellow group members and the transition team.

Data on the direct impacts of experiments from the participants' perspective, chiefly obtained through MSC interviews, revealed that people did benefit and participate in these ways, and social learning, experimentation and a level of empowerment occurred, leading to real changes in participants' lives that reduced their carbon emissions to varying degrees. However, issues were raised by some that suggested areas in which transition governance of the lab itself might have been improved, such as through more decentralisation of decision-making earlier in the life of the transition team.

There might also have been value in adopting a more structured approach, one that drew for example on transition management. This could among other things have resulted in clearer agenda setting and more systematic monitoring of and reflecting on experiments taken, their effectiveness and lessons for further action.

Acknowledgments: This research is funded by the CRC for Low Carbon Living Ltd. supported by the Cooperative Research Centres program, an Australian Government initiative. The authors would also like to thank Curtin University for providing funds for covering the costs to publish in open access and the City of Yarra for their involvement in Livewell Yarra.

Author Contributions: The first author Darren Sharp was responsible for the paper writing process, wrote large parts of the paper, and led the development of the framework as well as the data analysis. He conceived and designed experiments as the PhD student researcher. The second author Robert Salter contributed to the writing of the paper. He was the project initiator, conceived and designed experiments and supervised the first author. 
Conflicts of Interest: The authors declare no conflict of interest. The founding sponsors had no role in the design of the study; in the collection, analyses, or interpretation of data; in the writing of the manuscript, and in the decision to publish the results.

\section{References}

1. United Nations, Department of Economic and Social Affairs, Population Division. World Urbanization Prospects: The 2014 Revision; ST/ESA/SER.A/366; United Nations: New York, NY, USA, 2015.

2. Khanna, P. Beyond city limits. Foreign Policy, 6 August 2010; 120-128.

3. Loorbach, D. Transition Management: New Mode of Governance for Sustainable Development. Ph.D. Thesis, Erasmus University Rotterdam, Rotterdam, The Netherlands, 2007.

4. Liedtke, C.; Jolanta Welfens, M.; Rohn, H.; Nordmann, J. Living Lab: User-Driven Innovation for Sustainability. Int. J. Sustain. High. Educ. 2012, 13, 106-118. [CrossRef]

5. Australian Bureau of Statistics. Australian Social Trends (4102.0). April 2013. Available online: http:/ / www.abs.gov.au/AUSSTATS/abs@.nsf/Lookup/4102.0Main+Features30April+2013 (accessed on 20 December 2016).

6. Rowell, L.L.; Bruce, C.D.; Shosh, J.M.; Riel, M.M. (Eds.) The Palgrave International Handbook of Action Research; Palgrave Macmillan: New York, NY, USA, 2017; ISBN 978-1-137-44108-9.

7. Sengers, F.; Berkhout, F.; Wieczorek, A.J.; Raven, R.P.J.M. Experimenting in the city: Unpacking notions of experimentation for sustainability. In The Experimental City, 1st ed.; Evans, J., Karvonen, A., Raven, R., Eds.; Routledge: New York, NY, USA, 2016; ISBN 978-1138856202.

8. Loorbach, D.; Frantzeskaki, N.; Lijnis Huffenreuter, R. Transition management: taking stock from governance experimentation. J. Corp. Citizensh. 2015, 1, 48-67. [CrossRef]

9. Bulkeley, H.; Coenen, L.; Frantzeskaki, N.; Hartmann, C.; Kronsell, A.; Mai, L.; Marvin, S.; McCormick, K.; van Steenbergen, F.; Palgan, Y.V. Urban living labs: Governing urban sustainability transitions. Curr. Opin. Environ. Sustain. 2016, 22, 13-17. [CrossRef]

10. Bulkeley, H.; Breitfuss, M.; Coenen, L.; Frantzeskaki, N.; Fuenfschilling, L.; Grillitsch, M.; Hartmann, C.; Kronsell, A.; McCormick, K.; Marvin, S.; et al. Theoretical Framework: Working Paper on Urban Living Labs and Urban Sustainability Transitions; Deliverable 1.1.1.; Governance of Urban Sustainability Transitions (GUST): Lund, Sweden, 2015.

11. Voytenko, Y.; McCormick, K.; Evans, J.; Schliwa, G. Urban living labs for sustainability and low carbon cities in Europe: Towards a research agenda. J. Clean. Prod. 2016, 123, 45-54. [CrossRef]

12. Schumacher, J.; Feurstein, K. Living Labs-the user as co-creator. In Proceedings of the 2007 IEEE International Technology Management Conference (ICE), Sophia-Antipolis, France, 4-6 June 2007; pp. 1-6.

13. European Network of Living Labs Map. Available online: http://www.openlivinglabs.eu/llmap_cc (accessed on 10 August 2017).

14. Schumacher, J. Alcotra Innovation Project: Living Labs Definition, Harmonization Cube Indicators E Good Practices; Deliverable 3.1-Abridged Version and Other Good Practices; Alcotra Innovation: Genève, Switzerland, 2012.

15. McCormick, K. Urban Living Labs. GUST Policy Brief. 2016. Available online: https:/ /drive.google.com/ open?id=0BxnHQBC0SIPBeENSaUk5ZThoVHc (accessed on 10 August 2017).

16. Nevens, F.; Frantzeskaki, N.; Gorissen, L.; Loorbach, D. Urban Transition Labs: Co-creating transformative action for sustainable cities. J. Clean. Prod. 2013, 50, 111-122. [CrossRef]

17. Schliwa, S.; Evans, J.; McCormick, K.; Voytenko, Y. Living Labs and Sustainability Transitions-Assessing the Impact of Urban Experimentation. Presented at "Innovations in Climate Governance", Helsinki, Finland, 12-13 March 2015.

18. Heiskanen, E.; Jalas, M.; Rinkinen, J.; Tainio, P. The local community as a "low-carbon lab": Promises and perils. Environ. Innov. Soc. Transit. 2015, 14, 149-164. [CrossRef]

19. Markard, J.; Raven, R.; Truffer, B. Sustainability transitions: an emerging field of research and its prospects. Res. Policy 2012, 41, 955-967. [CrossRef]

20. Rip, A.; Kemp, R. Technological change. In Human Choice and Climate Change, Vol. II, Resources and Technology; Rayner, S., Malone, E.L., Eds.; Battelle Press: Columbus, OH, USA, 1998; pp. 327-399. ISBN 1574770462.

21. Jørgensen, U. Mapping and navigating transitions-The multi-level perspective compared with arenas of development. Res. Policy 2012, 41, 996-1010. [CrossRef] 
22. Geels, F.W. Technological transitions as evolutionary reconfiguration processes: A multi-level perspective and a case-study. Res. Policy 2002, 31, 1257-1274. [CrossRef]

23. Kemp, R.; Schot, J.; Hoogma, R. Regime shifts to sustainability through processes of niche formation: the approach of strategic niche management. Technol. Anal. Strateg. Manag. 1998, 10, 175-198. [CrossRef]

24. Farla, J.; Markard, J.; Raven, R.; Coenen, L. Sustainability transitions in the making: A closer look at actors, strategies and resources. Technol. Forecast. Soc. Chang. 2012, 79, 991-998. [CrossRef]

25. Loorbach, D.A. Transition Management for Sustainable Development: A Prescriptive, Complexity-Based Governance Framework. Gov. Int. J. Policy Adm. Inst. 2010, 23, 161-183. [CrossRef]

26. Wittmayer, J.; Van Steenbergen, F.; Quist, J.; Loorbach, D.; Hoogland, C. The Community Arena: A Co-Creation Tool for Sustainable Behaviour by Local Communities Methodological Guidelines; Deliverable 4.1; Ecologic Institute: Berlin, Germany, 2011.

27. Wittmayer, J.M.; Schäpke, N. Action, research and participation: Roles of researchers in sustainability transitions. Sustain. Sci. 2014, 9, 483-496. [CrossRef]

28. Bosman, R.; Rotmans, J. Transition governance towards a Bioeconomy: A Comparison of Finland and the Netherlands. Sustainability 2016, 8, 1017. [CrossRef]

29. Kretzmann, J.P.; McKnight, J.L. Building Communities from the inside Out: A Path toward Finding and Mobilizing a Community's Assets; ACTA Publications: Chicago, IL, USA, 1993; ISBN 978-0-87946-108-9.

30. Ideo. The Field Guide to Human-Centered Design; Ideo: Palo Alto, CA, USA, 2015; ISBN 978-0-9914063-1-9.

31. Hillgren, P.A.; Seravalli, A.; Emilson, A. Prototyping and infrastructuring in design for social innovation. CoDesign 2011, 7, 169-183. [CrossRef]

32. Dart, J.; Davies, R. A Dialogical, Story-based Evaluation Tool: the Most Significant Change Technique. Am. J. Eval. 2003, 24, 137-155. [CrossRef]

33. Roorda, C.; Wittmayer, J.; Henneman, P.; van Steenbergen, F.; Frantzeskaki, N.; Loorbach, D. Transition Management in the Urban Context: Guidance Manual; DRIFT, Erasmus University Rotterdam: Rotterdam, The Netherlands, 2014; 49p.

34. Sustainability Matters Staff. "Livewell Yarra" Low-Carbon Initiative Launched. 2015. Available online: http: / www.sustainabilitymatters.net.au/content/sustainability/news/-39-livewell-yarra-39-lowcarbon-initiative-launched-583366235 (accessed on 21 December 2016).

35. Livewell Yarra Transition Team. How to Guides. Available online: https://livewell.net.au/how-to-guides (accessed on 20 August 2017).

36. Reed, M.; Evely, A.C.; Cundill, G.; Fazey, I.R.A.; Glass, J.; Laing, A. What is social learning? Ecol. Soc. 2010, 15, r1. [CrossRef]

37. Block, P. Community: The Structure of Belonging; Barnett-Kohler: San Francisco, CA, USA, 2008; ISBN 1-60509-277-0.

38. Bos, J.J.; Brown, R.R.; Farrelly, M.A. A design framework for creating social learning situations. Glob. Environ. Chang. 2013, 23, 398-412. [CrossRef]

39. Schäpke, N.; Omann, I.; Wittmayer, J.M.; van Steenbergen, F.; Mock, M. Linking Transitions to Sustainability: A Study of the Societal Effects of Transition Management. Sustainability 2017, 9, 737.

40. Van Eijndhoven, J.; Frantzeskaki, N.; Loorbach, D. Connecting Long and Short-Term via Envisioning in Transition Arenas. In Water Governance as Connective Capacity; Edelenbos, J., Bressers, N., Scholten, P., Eds.; Ashgate Publications: London, UK, 2013; ISBN 9781409447467.

41. Greening the Economy: Sustainable Cities. Available online: https://www.coursera.org/learn/gtesustainable-cities/ (accessed on 21 August 2017).

42. Schliwa, G.; McCormick, K. Living labs. In The Experimental City, 1st ed.; Evans, J., Karvonen, A., Raven, R., Eds.; Routledge: New York, NY, USA, 2016; ISBN 978-1138856202.

(C) 2017 by the authors. Licensee MDPI, Basel, Switzerland. This article is an open access article distributed under the terms and conditions of the Creative Commons Attribution (CC BY) license (http:/ / creativecommons.org/licenses/by/4.0/). 